\title{
Cisplatin Weekly Versus Every 3 Weeks Concurrently with Radiotherapy in the Treatment of Locally Advanced Head and Neck Squamous Cell Carcinomas: What Is the Best Dosing and Schedule?
}

\author{
Karim Mashhour*, Wedad Hashem
}

\begin{abstract}
Purpose: The aim of this prospective randomized study is to compare cisplatin at 2 dose levels given concurrently with intensity modulated radiation therapy (IMRT) in the treatment of locally advanced HNSCC. The main objectives were to evaluate treatment toxicities, loco-regional control, tumor response and patients compliance. Methods: Patients were randomized into two groups that either received $30 \mathrm{mg} / \mathrm{m}^{2}$ cisplatin weekly (arm A) or $100 \mathrm{mg} / \mathrm{m}^{2}$ once every 3 weeks (arm B). Radiotherapy prescribed dose was 70Gy in 33 fractions. Treatment adverse events were documented. Results: Sixty patients with locally advanced HNSCC were included in this study. Recruitment started at the beginning of July 2016 and ended in July 2019. The Median follow-up was 24 months. Acute non-hematological toxicities of grade 3 or higher during the treatment course were significantly more observed in Arm B patients (76.6\%) compared to Arm A patients (56.6\%) with a P-value of 0.007. Hematological toxicities in the form of anemia, leucopenia and neutropenia were also significantly higher in Arm B patients with a p-value of $0.435,0.002$ and 0,002, respectively. The median 2 year loco-regional control rate in Arm B was 72.8\% versus 57.6\% in Arm A with a p-value of 0.015 . Complete responses were similar between both groups (77\%). Compliance to treatment was better in Arm A with 70\% of the patients received at least 6 weekly doses where as $60 \%$ of the patients in Arm B completed the three cycles of treatment and $40 \%$ received only 2 cycles. Conclusion: Once weekly low dose cisplatin treatment showed lower acute toxicity and a better compliance compared to once every 3 weeks high dose cisplatin treatment at the expense of a lower loco-regional control.
\end{abstract}

Keywords: Cisplatin- weekly- every 3 weeks- IMRT

Asian Pac J Cancer Prev, 21 (3), 799-807

\section{Introduction}

Cisplatin based concurrent chemo-radiotherapy (CRT) protocols is the standard of care in treating locally advanced head and neck squamous cell carcinoma (HNSCC). An improvement of loco-regional control and survival has been observed with administrating cisplatin every 3 weeks using the high dose (HD) regimen $\left(100 \mathrm{mg} / \mathrm{m}^{2}\right)$ in randomized clinical trials (Adelstein et al., 1990; Adelstein et al., 2003; Forastiere et al., 2013; Cooper et al., 2004; Bernier 2004; Bernier et al., 2006 ).

One of the major concerns of using HD cisplatin is the high incidence of acute toxicity during the treatment course which led to suboptimal adherence and compliance to treatment in nearly half of the patients in clinical studies (Ho et al., 2008; Gupta et al., 2009; Otty et al., 2011). On the other hand, the low dose (LD) weekly cisplatin $\left(40 \mathrm{mg} / \mathrm{m}^{2}\right)$ is more tolerable regarding toxicity profile
(Rawat et al., 2016), ease of administration (Rades et al., 2016; Fayette et al., 2015) and lower necessity for supportive care and inpatient admissions (Marcu et al., 2003).

The weekly regimen is widely accepted and included in official international guidelines (Sharma et al., 2010; Ghosh- Laskar et al., 2016; Ghosh-Laskar et al., 2016; D'cruz et al., 2013; NCCN V2 2017) but its toxicity and efficacy compared to HDC across several retrospective (Geeta et al., 2006; Oosting et al., 2016; Espeli et al., 2012; Geiger et al., 2014) and prospective retrospective (Uygun et al., 2009; Tsan et al., 2012; Sahoo et al., 2017) clinical studies was evaluated on a small number of patients. Most of the comparative data stems from meta-analyses and systemic reviews retrospective (Negi et al., 2016; Guan et al., 2016; Szturz et al., 2017).

The optimal scheduling and dosing of cisplatin in the adjuvant or definitive treatment of HNSCC is still

Department of Clinical Oncology, Kasr Al-Einy Sschool of Medicine, Cairo University, Egypt. *For Correspondence: karim.mashhour.81@gmail.com 
uncertain and requires answers from large randomized trials.

\section{Aim of work}

The aim of this randomized prospective study is to compare cisplatin at 2 dose levels either given weekly $\left(30 \mathrm{mg} / \mathrm{m}^{2}\right)$ versus every 3 weeks $\left(100 \mathrm{mg} / \mathrm{m}^{2}\right)$ concurrently with intensity modulated radiation therapy (IMRT) in the treatment of locally advanced HNSCC. The main objectives of the current study were to evaluate treatment toxicities, loco-regional control, tumor response, patients' tolerance and compliance.

\section{Materials and Methods}

A written informed consent was a pre-requisite for the patients to be enrolled in this clinical study.

\section{Data collection and selection criteria}

The study included patients with locally advanced head and neck cancers (stages 3 and 4), with a histo-pathologically confirmed squamous or undifferentiated carcinomas, age range from 18 to 70 years, Eastern Co-operative Oncology Group (ECOG) performance status (PS) from 0-2 and with a creatinine clearance $>60 \mathrm{ml} / \mathrm{min}$. Patients with metastatic disease, received neo-adjuvant chemotherapy or with history of another malignant disease were excluded from the study. Human papilloma virus (P16) testing was not done due to unavailability.

\section{Pre-treatment evaluation}

Patients underwent a thorough pre-treatment clinical evaluation, including a complete detailed medical history and physical examination, computed tomography (CT), PET/CT and Magnetic resonance imaging (MRI) of head and neck region with intravenous contrast were obtained according to the clinician prescription, direct flexible endoscopic examination, X-ray of the chest or thoracic CT. Associated medical Comorbidities were assessed and recorded.

With the aid of a randomization table, patients were randomly assigned 1:1 into two arms (Arm A: low dose cisplatin and Arm B: high dose cisplatin). For the low dose arm, cisplatin was administrated concurrently with radiotherapy at a planned dose of $30 \mathrm{mg} / \mathrm{m}^{2}$ weekly while for the high dose arm the planned protocol was $100 \mathrm{mg} / \mathrm{m}^{2}$ every 3 weeks (on days 1, 22, and 43), respectively.

\section{Radiotherapy details}

The patients set up was in supine position and immobilization was done with the aid of a S-shaped head and shoulder thermoplastic mask (Aquaplast, USA). A planning CT scan with intravenous contrast was performed with a slice thickness of $2.5 \mathrm{~mm}$ starting from the vertex of the skull down to mid-chest. The full set of images were then transferred to the Eclipse treatment planning system (v 8.6).

A senior radiation oncologist was responsible for contouring of the cases. The gross tumor volume (GTV) was the macroscopic disease including all positive cervical lymph nodes as detected clinically and/or radiologically.
A clinical target volume (CTV) of $1 \mathrm{~cm}$ around the GTV was done. Other CTV's delineated were the high risk CTV including areas at high risk of harboring microscopic disease and low risk CTV which included low level cervical lymph nodes in cases with node negative disease. The contouring of lymph node stations were based on many published international consensus guidelines (Gregoire et al. 2003). Generally, The planning target volume (PTV) margin was a $5 \mathrm{~mm}$ expansion from each CTV taking into consideration potential setup errors

Patients were planned for inverse IMRT with the modality of step and shoot using Eclipse Planning System (version 8.6, from Varian Medical Systems). An experienced physicist in head and neck treatment planning was assigned in this study. The doses prescribed were similar to the RTOG 0225 study (Lee et al.2009), the dose to the PTV primary was 69.96 Gy in 2.12 Gy per fraction, the dose to the PTV high risk disease was 59.4 Gy in 1.8 Gyper fractions and the dose to the PTV low risk disease was $54.12 \mathrm{~Gy}$ in $1.64 \mathrm{~Gy}$ per fraction. Total number of fractions was 33 delivered 5 days a week.

\section{Chemotherapy details}

With respect to Arm A, cisplatin at a dose of $30 \mathrm{mg} / \mathrm{m}^{2}$ was administered on weekly basis in $500 \mathrm{ml} 0.9 \%$ sodium chloride over 1 hour during the treatment course to a maximum of seven cycles. Pre and post- treatment hydration, corticosteroids, antiemetics, intravenous Mannitol 20\% and supportive treatment was administrated for each patient. Potassium chloride and magnesium sulfate infused over 60 minutes each was necessary with each infusion. Regarding Arm B, cisplatin at a dose of $100 \mathrm{mg} / \mathrm{m}^{2}$ was given intravenously in 1 litre $0.9 \%$ sodium chloride over 2 hours every 3 weeks at days 1, 22 and 43. More vigorous hydration and anti-emetics were adjusted to the every 3 weeks protocol in view of being a higher nephrotoxic and ematogenic risk protocol.

Doses ere modified based on the results of the routine laboratory tests done before chemotherapy cycle. Chemotherapy administration was allowed if the level of hemoglobin was more than $10 \mathrm{gm} / \mathrm{dl}$, Platelet count of more than $>100 \times 10^{9} / \mathrm{L}$, total leukocytic count (TLC) more than $4.0 \times 10^{9} / \mathrm{L}$ with an absolute neutrophilic count (ANC) of more than $2.0 \times 10^{9} / \mathrm{L}$. Renal functions was assessed regularly. In this study, growth factors were not used.

Administration of at least six weekly and two out of three chemotherapy infusions in our study was defined as adequate chemotherapy exposure in Arms A and B, respectively. The planned cumulative dose was $200 \mathrm{mg} / \mathrm{m}^{2}$.

\section{Toxicity evaluation}

Evaluation of toxicity was based on the fourth version of Common Toxicity Criteria for Adverse Events [CTCAE v. 4.03] (CTCAE 2009).

Scoring of acute toxicity was documented on weekly basis from the beginning of radiotherapy till 3 months post-treatment. In case of documentation of multiple occurrences, grading was based on the severest grade of that particular event.

Insertion of a nasogastric tube was indicated in 
case of grade 3 or more dysphagia and progressive weight loss during treatment. Weekly laboratory testing was performed for all patients in both arms and chemotherapy dosing was modified accordingly.

\section{Statistical analysis}

All statistical analysis was done using the SPSS software (Statistical package for social science) v.19. Description statistics were presented as number and percentage (frequency distribution).

On follow up, absence of any visible tumor re-growth in the primary area and draining lymphatics was defined as loco-regional control (LRC). Chi-square test was used to calculate the degree of significance of the selected parameters between both groups. Hazard ratios for the risk of death were estimated using Cox regression models. A value was considered significant when $\mathrm{p}$ is $<0.05$.
Concurrent Cisplatin Weekly versus 3 Weeks in LAHNC

\section{Results}

\section{Patient and tumor characteristics}

Sixty patients diagnosed with locally advanced HNSCC were recruited in this study between July 2016 and July 2019. Patients were equally randomized to Arm A (low dose cisplatin ) and Arm B (high dose cisplatin), respectively. The age of the patients ranged from 56 to 65 years (median 61 years). The majority of patients were of male gender $(73.3 \%$ and $80 \%)$ and habituated to the use of tobacco (40\% and 50\%). In both groups, laryngeal SCC was the commonest subsite involved comprising $33.3 \%$ and $26.7 \%$ of Arms A and B, respectively. At presentation, the majority of patients presented with a T3 tumor $(50 \%$ and $43.3 \%$ ) and $\mathrm{N} 2$ disease ( $46.6 \%$ and $50 \%$ ). The intent of treatment was nearly equal in both arms, half of the patients were treated by adjuvant chemo-radiation in view of having positive margins or extra-capsular extension while the other half were treated definitively. The patient

Table 1. Illustrates the Patient and Tumoral Characteristics of both Arms Involved in the Study

\begin{tabular}{|c|c|c|c|}
\hline \multirow[t]{2}{*}{ Characteristic } & Arm A \% $(n=30)$ & Arm B \% $(n=30)$ & \multirow[t]{2}{*}{ p-value } \\
\hline & Low dose cisplatin & High dose cisplatin & \\
\hline \multicolumn{4}{|l|}{ Gender } \\
\hline Male & $22(73.3 \%)$ & $24(80 \%)$ & \multirow[t]{2}{*}{4.48} \\
\hline Female & $8(26.7 \%)$ & $6(20 \%)$ & \\
\hline Age, median & $60(56-64)$ & $61(57-65)$ & 0.15 \\
\hline \multicolumn{4}{|l|}{ Smoking status } \\
\hline Current & $12(40 \%)$ & $15(50.0 \%)$ & \multirow{3}{*}{0.72} \\
\hline Former & $10(33.3 \%)$ & $9(30.0 \%)$ & \\
\hline Never & $8(26.7 \%)$ & $6(20.0 \%)$ & \\
\hline \multicolumn{4}{|l|}{ Tumor site } \\
\hline Oral cavity & $5(16.7 \%)$ & $6(20.0 \%)$ & \multirow{5}{*}{0.78} \\
\hline Oropharynx & $6(20.0 \%)$ & $5(16.7 \%)$ & \\
\hline Nasopharynx & $4(13.3 \%)$ & $7(23.3 \%)$ & \\
\hline Larynx & $10(33.3 \%)$ & $8(26.7 \%)$ & \\
\hline Hypopharynx & $5(16.7 \%)$ & $4(13.3 \%)$ & \\
\hline \multicolumn{4}{|l|}{ Stage at diagnosis } \\
\hline III & $10(33.3 \%)$ & $9(30.1 \%)$ & \multirow{3}{*}{0.82} \\
\hline IVA & $11(36.6 \%)$ & $11(36.6 \%)$ & \\
\hline IVB & $9(30.1 \%)$ & $10(33.3 \%)$ & \\
\hline \multicolumn{4}{|l|}{ T-stage } \\
\hline $\mathrm{T} 1$ & $1(3.33 \%)$ & $0(0 \%)$ & \multirow{4}{*}{0.68} \\
\hline $\mathrm{T} 2$ & $4(13.37 \%)$ & $5(16.7 \%)$ & \\
\hline $\mathrm{T} 3$ & $15(50.0 \%)$ & $13(43.3 \%)$ & \\
\hline $\mathrm{T} 4$ & $10(33.3 \%)$ & $12(40.0 \%)$ & \\
\hline \multicolumn{4}{|l|}{ N-stage } \\
\hline No & $4(13.3 \%)$ & $3(10.0 \%)$ & \multirow{4}{*}{0.36} \\
\hline N1 & $9(30.1 \%)$ & $10(33.3 \%)$ & \\
\hline N2 & $14(46.6 \%)$ & $15(50.0 \%)$ & \\
\hline N3 & $3(10.0 \%)$ & $2(6.7 \%)$ & \\
\hline \multicolumn{4}{|l|}{ Intent of treatment } \\
\hline Adjuvant & $16(53.3 \%)$ & $15(50.0 \%)$ & \\
\hline Definitive & $14(46.7 \%)$ & $15(50.0 \%)$ & 0.41 \\
\hline
\end{tabular}


Table 2. Shows the Non-hematological Adverse Events Encountered During the Treatment Course in both Arms

\begin{tabular}{|c|c|c|c|}
\hline Hematological & $\operatorname{Arm~A} \%(n=30)$ & Arm B \% $(n=30)$ & p-value \\
\hline Adverse event & Low dose cisplatin & High dose cisplatin & \\
\hline \multicolumn{4}{|l|}{ Mucositis } \\
\hline G2 & $14(46.6 \%)$ & $16(53.3 \%)$ & \multirow{4}{*}{0.254} \\
\hline G3 & $12(40 \%)$ & $11(36.6 \%)$ & \\
\hline G4 & $4(13.4 \%)$ & $3(10.1 \%)$ & \\
\hline G5 & $0(0 \%)$ & $0(0 \%)$ & \\
\hline \multicolumn{4}{|l|}{ Dysphagia } \\
\hline G2 & $16(53.3 \%)$ & $' 10(33.3 \%)$ & \multirow{4}{*}{1.000} \\
\hline G3 & $12(40 \%)$ & $16(53.3 \%)$ & \\
\hline G4 & $2(6.7 \%)$ & $4(13.4 \%)$ & \\
\hline G5 & $0(0 \%)$ & $0(0 \%)$ & \\
\hline \multicolumn{4}{|l|}{ Nausea/Vomiting } \\
\hline G2 & $25(86.6 \%)$ & $24(80 \%)$ & \multirow[t]{4}{*}{0.436} \\
\hline G3 & $5(13.4 \%)$ & $5(16.7 \%)$ & \\
\hline G4 & $0(0 \%)$ & $1(3.3 \%)$ & \\
\hline G5 & $0(0 \%)$ & $0(0 \%)$ & \\
\hline \multicolumn{4}{|l|}{ Xerostomia } \\
\hline G2 & $25(83.3 \%)$ & $24(80 \%)$ & \multirow{4}{*}{0.356} \\
\hline G3 & $5(16.7 \%)$ & $6(20 \%)$ & \\
\hline G4 & $0(0 \%)$ & $0(0 \%)$ & \\
\hline G5 & $0(0 \%)$ & $0(0 \%)$ & \\
\hline \multicolumn{4}{|l|}{ Dermatitis } \\
\hline G2 & $26(86.6 \%)$ & $27(90 \%)$ & \multirow{4}{*}{1.000} \\
\hline G3 & $4(13.3 \%)$ & $3(10 \%)$ & \\
\hline G4 & $0(0 \%)$ & $0(0 \%)$ & \\
\hline G5 & $0(0 \%)$ & $0(0 \%)$ & \\
\hline \multicolumn{4}{|l|}{ Laryngeal oedema } \\
\hline G2 & $25(83.3 \%)$ & $25(83.3 \%)$ & \multirow{4}{*}{0.324} \\
\hline G3 & $5(16.7 \%)$ & $4(13.3 \%)$ & \\
\hline G4 & $0(0 \%)$ & $1(3.33 \%)$ & \\
\hline G5 & $0(0 \%)$ & $0(0 \%)$ & \\
\hline Acute toxicity grade 3 or higher & $17(56.6 \%)$ & $23(76.6 \%)$ & 0.007 \\
\hline
\end{tabular}

and tumoral characteristics are outlined in Table 1.

\section{Non-hematological toxicities}

Acute toxicities of grade 3 or higher during the treatment course was significantly more observed in Arm B patients (23 patients $\{76.6 \%\}$ ) compared to Arm A patients (17 patients $\{56.6 \%\})$ with a P-value of 0.007 . There was no statistically significant difference between both arms for each individual toxicity. Table 2 outlines the non-hematological adverse events encountered in both arms.

14 patients (46.6\%) in Arm A developed G2 mucositis while 16 patients $(53.3 \%)$ in Arm B had the same mucositis grade with an insignificant p-value (0.254). Most of the patients experienced G2 and G3 mucositis in both arms while a minority of patients had a G4 adverse event. Patients who experienced G4 mucositis were hospitalized and their radiotherapy sessions were delayed. A feeding gastrostomy tube was inserted in these patients and after being successfully recovered, the treatment course was continued.

G2 dysphagia was more pronounced in Arm A patients but higher grades ( 3 and 4 ) were more frequent in the high dose cisplatin arm (p-value: 1.000). With respect to other acute non-hematological adverse events, the number of patients who developed G2 and 3 nausea and vomiting, xerostomia, dermatitis and laryngeal oedema was closely similar in both groups with insignificant p-values. Only 1 patient in Arm B had a G4 nausea and vomiting and another patient in the same Arm had a G4 laryngeal oedema.

\section{Hematological toxicities}

Fourteen patients (46.6\%) in Arm B developed grade 2 anemia compared to 10 patients ( $33.3 \%$ ) in Arm A (p-value: 0.435). Similarly, G3 anemia was slightly higher in the high cisplatin dose group and was seen in 7 patients versus 5 patients in the low cisplatin dose arm. No grade 


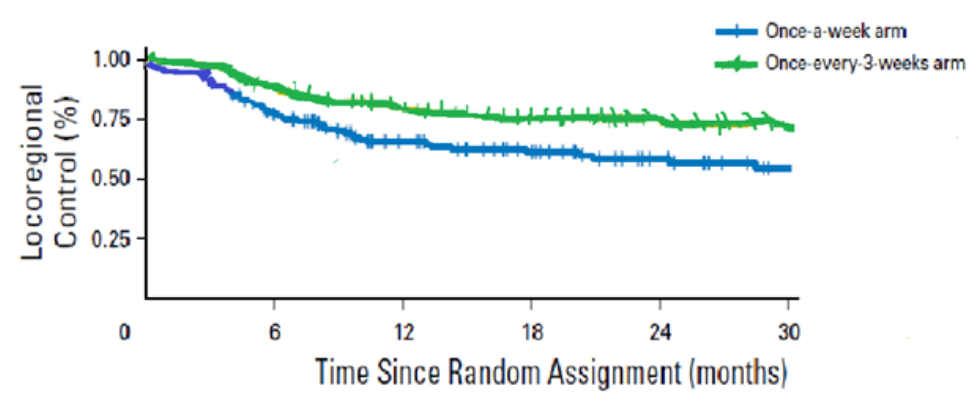

Figure 1. Loco-Regional Control Rate (\%) Plotted against Time since Random Assignment (months) in both Arms (Arm A in blue and Arm B in green) with an Absolute Difference of 15.2\% in both Arms Regarding the Loco-regional Recurrence Rates

4 anemia was noticed in both groups.

G2 and 3 Leucopenia and neutropenia were significantly more noticed in Arm B patients compared to Arm A (p: 0.002), respectively. 18 patients $(60 \%)$ had a G2 leucopenia in Arm B while 12 patients (40\%) in Arm A developed the same grade of leucopenia. Similarly, the highest recorded neutropenia grade was grade 2 and it was encountered in half of the patients in the high dose cisplatin arm as compared to 6 patients $(20 \%)$ in the low dose weekly cisplatin group. Only 1 patient in Arm B developed a G4 leucopenia but grade 4 Neutropenia was not noticed in this patient.

With respect to thrombocytopenia as an adverse event, four patients in each group (13.3\%) developed G2 (p: 0.713) where as G3 was seen in a single patient in Arm A and in 3 patients (10\%) in Arm B. No G4 thrombocytopenia was recorded in both arms. Table 3 shows the hematological adverse events documented in both arms.

\section{Loco-regional Control and tumor response}

The median follow up for the patients was 24 months (range 15-37 months). The median 2 year loco-regional control rate in patients treated with high dose cisplatin (Arm B) was $72.8 \%$ versus $57.6 \%$ in the patients treated with low dose cisplatin weekly (Arm A) (p-value:0.015; hazard ratio 1.78 ) with an absolute difference of $15.2 \%$ in both arms regarding the loco-regional recurrence rates. Figure 1 demonstrates the locoregional control rates as a percentage $(\%)$ in both arms.

Regarding the correlation between both arms and tumor response in our study, complete response (CR) was seen in $77 \%$ versus $76 \%$ in Arms A and B, respectively while partial response (PR) was seen in $13.2 \%$ versus $12.6 \%$ in Arms A and B, successively. After 2 months of treatment completion, stationary disease (SD) was observed in $4.6 \%$

Table 3. Describes the Hematological Adverse Events Recorded During the Treatment of Arms A and B, Respectively.

\begin{tabular}{|c|c|c|c|}
\hline Hematological & $\operatorname{Arm~A} \%(n=30)$ & Arm B \% $(n=30)$ & p-value \\
\hline Adverse event & Low dose cisplatin & High dose cisplatin & \\
\hline \multicolumn{4}{|l|}{ Anemia } \\
\hline $\mathrm{G} 2$ & $10(33.3 \%)$ & $14(46.6 \%)$ & \multirow{4}{*}{0.435} \\
\hline G3 & $5(16.7 \%)$ & $7(23.3 \%)$ & \\
\hline G4 & $0(0 \%)$ & $2(6.6 \%)$ & \\
\hline G5 & $0(0 \%)$ & $0(0 \%)$ & \\
\hline \multicolumn{4}{|l|}{ Leucopenia } \\
\hline G2 & $12(40 \%)$ & $18(60 \%)$ & \multirow{4}{*}{0.002} \\
\hline G3 & $6(20 \%)$ & $10(33.3 \%)$ & \\
\hline G4 & $0(0 \%)$ & $1(3.3 \%)$ & \\
\hline G5 & $0(0 \%)$ & $0(0 \%)$ & \\
\hline \multicolumn{4}{|l|}{ Neutropenia } \\
\hline G2 & $6(20 \%)$ & $10(50 \%)$ & \multirow{4}{*}{0.002} \\
\hline G3 & $3(10 \%)$ & $6(20 \%)$ & \\
\hline G4 & $0(0 \%)$ & $0(0 \%)$ & \\
\hline G5 & $0(0 \%)$ & $0(0 \%)$ & \\
\hline \multicolumn{4}{|c|}{ Thrombocytopenia } \\
\hline $\mathrm{G} 2$ & $4(13.3 \%)$ & $4(13.3 \%)$ & \multirow{4}{*}{0.713} \\
\hline G3 & $1(3.3 \%)$ & $3(10 \%)$ & \\
\hline G4 & $0(0 \%)$ & $0(0 \%)$ & \\
\hline G5 & $0(0 \%)$ & $0(0 \%)$ & \\
\hline
\end{tabular}




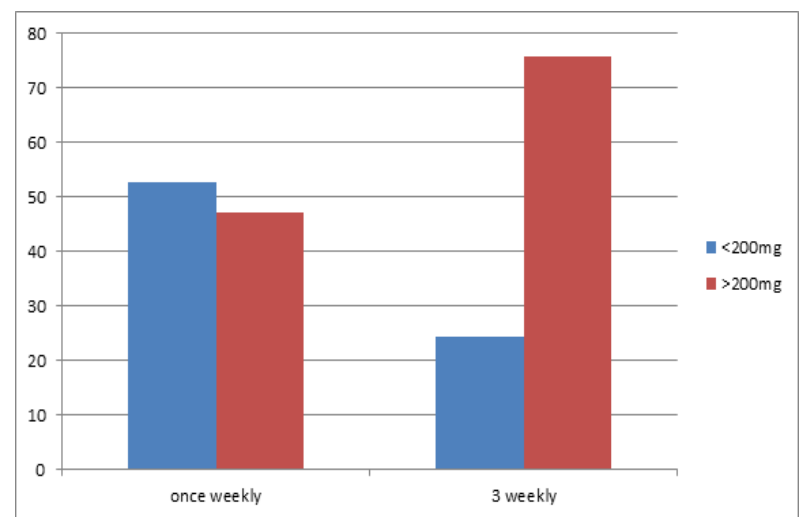

Figure 2. Bar Chart Comparing Weekly vs 3 Weekly Schedule with $200 \mathrm{mg} / \mathrm{m}^{2}$ as a Cut-off Cumulative Cisplatin Dose.

in Arm A and 4.1\% in Arm B.

\section{Cumulative cisplatin dose and patients compliance}

$75 \%$ of the patients in Arm B who received cisplatin high dose every 3 weeks had a higher cumulative cisplatin dose (at least $200 \mathrm{mg} / \mathrm{m}^{2}$ ) versus $46 \%$ of patients in Arm A (Figure 2) with a statistically significant p-value of 0.003 (Figure 2).

The median or average cumulative dose of cisplatin was $170 \mathrm{mg} / \mathrm{m}^{2}$ in the weekly cisplatin group (Arm A) while in the every 3 weeks schedule (Arm B ) the median dose was $200 \mathrm{mg} / \mathrm{m}^{2}$ ( $\mathrm{p}=$ value: 0.004$)$.

With respect to the patients compliance to chemotherapy, $60 \%$ of the patients in Arm B completed the three cycles of treatment and $40 \%$ received only 2 cycles while $70 \%$ of patients in Arm A were able to receive at least 6 cycles of weekly chemotherapy with minor reductions in chemotherapy dosing due to acute side effects.

\section{Discussion}

The management of locally advanced head and neck cancers represents a big challenge for both the patient and the treating physician. The compliance and adherence to the treatment regimen in this area is greatly affected by the close proximity of multiple risk structures with critical functions and hence affecting the patients' quality of life. Data from many randomized studies and meta-analysis strongly recommends using platinum based concomitant chemo-radiation as the treatment of choice in locally advanced HNSCC (Pignon et al., 2000; Pignon et al., 2007; Pignon et al., 2009).

In two large randomized trials, the administration of high dose cisplatin $\left(100 \mathrm{mg} / \mathrm{m}^{2}\right)$ once every 3 weeks concurrently with radiation is the standard of care in treating head and neck cancers (Bernier et al., 2004; Cooper et al., 2004). The weekly dosing of cisplatin may show a lower toxicity profile and similar efficacy. Delivering small doses of weekly cisplatin has 2 main advantages over the high dose regimen. First, low doses of weekly chemotherapy have a radio-sensitizing effect which enables the cells to be recruited to the mitotic phase and hence more cell kill. Second, administrating the small doses leads to a lower morbidity without having a negative impact on efficacy (Kurihara et al., 1996).

Marcu et al., (2006) have performed many studies on the radio-sensitizing effect of cisplatin. Their data showed improvement in radio-sensitization with the administration of low doses of weekly cisplatin. Their model demonstrated a $35 \%$ tumor control improvement when cisplatin was administrated daily versus $6 \%$ only when cisplatin was given weekly concurrently with radiotherapy. Their review found that low dose cisplatin administrated daily in six out of the sixteen trials had a better tumor control with lower toxicity in contrast to the weekly regimen (Marcu et al., 2003). Administration of daily cisplatin during head and neck irradiation might be an interesting point of research in future studies.

Despite the strong evidence we have from clinical trials regarding the gain of adding chemotherapeutics to enhance radiation cell kill, still there is a considerable controversy regarding choosing the best and optimal dosing of chemotherapy due to heterogeneous study designs and different chemo-radiotherapy combinations and protocols (Ang et al., 2004). The optimal dosing and scheduling of cisplatin concurrently with radiation therapy had led to various comparisons.

In our prospective randomized study, we compared weekly cisplatin at a dose of $30 \mathrm{mg} / \mathrm{m}^{2}$ weekly for six-seven weeks to $100 \mathrm{mg} / \mathrm{m}^{2}$ every 3 weeks for 3 cycles during definitive or adjuvant chemo-radiotherapy of head and neck cancers. Radiotherapy was delivered using IMRT in both arms. An important note to be considered that old trials addressing concurrent chemo-radiation mostly used 3D-conformal radiotherapy which might be a reason accounting for the higher grades of adverse events irrespective to the dosing or scheduling of chemotherapy. To our own knowledge, this is the first prospective randomized study in the Middle East and North African region comparing 2 different dose levels of cisplatin in head and neck radiotherapy. The number of patients recruited was 30 in each arm. There were some limitations in our study including the small sample size and inability to perform the pathological testing of P16 which is not yet validated in our pathology department. However, evaluation of the adverse events and loco-regional control was adequately addressed inspite of the short follow up period.

In our study, we found that weekly cisplatin at $30 \mathrm{mg} / \mathrm{m}^{2}$ had lower adverse events compared to the 3 weekly regimen but the locoregional control was better in the high dose arm. The results of our study is in accordance with the results of Noronha et al., (2017) where the authors found a superior locoregional control in the high cisplatin arm and also with higher toxicity profile compared to the low dose weekly arm. The authors stated that the weekly regimen should be the preferred regimen in treating head and neck cancers in the adjuvant setting.

Though level 1 evidence is lacking, weekly cisplatin has wide replaced the 3 weekly regimen in many clinical trials (Sharma et al., 2010; Ghosh- Laskar et al., 2016; Ghosh-Laskar et al., 2016) and in routine medical practice (Ho et al., 2008; Gupta et al. 2009; Otty et al., 2011; Rawat et al., 2016; Rades et al., 2016; Fayette et al., 2015; Traynor et al., 2010; Boulmay et al., 2009; 
Ghosh et al., 2015; Geeta et al., 2006; Oosting et al., 2016; Espeli et al., 2012; Geiger et al., 2014; Tsan et al., 2012; Sahoo et al., 2017; Quon et al., 2011). According to our results, we endorse using weekly cisplatin in view of the lower incidence of the acute toxicities compared to the high dose group. The schedule and dose of weekly cisplatin is variable in different clinics and centers. A phase three trial using cisplatin $20 \mathrm{mg} / \mathrm{m}^{2}$ in unresectable locally advanced HNSCC versus radical radiotherapy didn't gain any advantage in overall survival (Sharma et al., 2010). In locally advanced nasopharyngeal and oropharyngeal cancers, weekly cisplatin at a dose of $40 \mathrm{mg} / \mathrm{m}^{2}$ concurrently with radiotherapy compared to radiotherapy alone achieved better loco-regional control but with a higher toxic side effects (Tsan et al., 2012; Chan et al., 2002; Chan et al., 2005). In an important meta-analysis by Bauml et al.,(2019) which is based on the Veterans Affairs database, they assessed the impact of concurrent weekly cisplatin at $40 \mathrm{mg} / \mathrm{m}^{2}$ to 3 -weekly $100 \mathrm{mg} / \mathrm{m}^{2}$ in 2,901 patients and concluded that both regimes had similar overall survival in both groups with a more favorable acute toxicity profile in the weekly cisplatin arm. Trials investigating a flat cisplatin dose of $50 \mathrm{mg}$ as a weekly sensitizer with radiotherapy resulted in lower loco-regional recurrences and better survival when compared to radiation therapy alone (Bachaud et al., 1996). We used the $30 \mathrm{mg} / \mathrm{m}^{2}$ in our study in Arm A versus the standard of care which is cisplatin $100 \mathrm{mg} / \mathrm{m}^{2}$ in Arm B concurrently with radiotherapy. The median or average cumulative dose of cisplatin was $170 \mathrm{mg} / \mathrm{m}^{2}$ in the weekly cisplatin group which suggests a satisfactory cisplatin exposure. Currently, two phase III trials are ongoing and conducted to compare weekly cisplatin with $40 \mathrm{mg} / \mathrm{m}^{2}$ versus $100 \mathrm{mg} / \mathrm{m}^{2}$ (Szturz et al., 2017; Kunieda et al., 2014)

Most of the trials investigating the high dose cisplatin $100 \mathrm{mg} / \mathrm{m}^{2}$ showed improved and better efficacy but with increased toxicity. In the intergroup trials, rates of acute toxicities were $85 \%$ with definitive chemoradiotherapy and $77 \%$ in the post-operative setting; $76.6 \%$ of patients in Arm B in or study experienced acute toxicities of grade 3 or higher during the treatment course (Cooper et al., 2004; Adelstein et al., 2003). The increased rate of adverse events does not compromise the patients compliance, in the EORTC trial nearly $79 \%$ of the patients received 2 or more chemotherapy cycles where as in our study $60 \%$ of the patients in Arm B completed the three cycles of treatment and $40 \%$ received only 2 cycles while $70 \%$ of patients in Arm A were able to receive at least 6 cycles of weekly chemotherapy with minor reductions in chemotherapy dosing (Bernier et al., 2004). The higher percentage of compliance in Arm A in our study could be explained by the fact that patients receiving weekly cisplatin are easier to be regularly seen and monitored for adverse events more than the patients who receive the high dose of cisplatin every 3 weeks.

In conclusion, concurrent chemoradiotherapy using high dose cisplatin administrated as $100 \mathrm{mg} / \mathrm{m}^{2}$ every 3 weeks is the current standard of care in treating locally advanced head and neck squamous cell carcinoma. Of increased use recently is giving cisplatin at a low dose weekly during the radiotherapy course due to lower adverse advents and convenience. Nevertheless, the effectiveness of both schedules has not adequately compared. In our study, once weekly low dose cisplatin treatment showed lower acute toxicity and a better compliance compared to once every 3 weeks high dose cisplatin treatment but with a lower loco-regional control.

\section{Conflict of interest}

On behalf of all authors, the corresponding author states that there is no conflict of interest. There was no funding for this randomized trial.

\section{References}

Adelstein DJ, Sharan VM, Earle AS, et al (1990) Simultaneous versus sequential combined technique therapy for squamous cell head and neck cancer. Cancer, 65, 1685-91.

Adelstein DJ, Li Y, Adams GL, et al (2003) An intergroup phase III comparison of standard radiation therapy and two schedules of concurrent chemoradiotherapy in patients with unresectable squamous cell head and neck cancer. J Clin Oncol, 21, 92-8.

Ang KK (2004). Concurrent radiation chemotherapy for locally advanced head and neck cancer: Are we addressing burning subjects?. J Clin Oncol, 22, 4657-9

Bachaud JM, Cohen-Jonathan E, Alzieu C, et al (1996). Combined postoperative radiotherapy and weekly cisplatin infusion for locally advanced head and neck carcinoma: Final report of a randomized trial. Int J Radiat Oncol Biol Phys, 36, 999-1004,

Bauml JM, Vinnakota R, Anna Park Y, et al (2019). Cisplatin every 3 weeks versus weekly with definitive concurrent radiotherapy for squamous cell carcinoma of the head and neck . J Nat Cancer Instit, 111, 490-7.

Bernier J, Cooper JS, Pajak TF, et al (2005). Defining risk levels in locally advanced head and neck cancers: a comparative analysis of concurrent postoperative radiation plus chemotherapy trials of the EORTC (\#22931) and RTOG (\# 9501). Head Neck, 27, 843-50.

Bernier J, Domenge C, Ozsahin M, et al (2004). Postoperative irradiation with or without concomitant chemotherapy for locally advanced head and neck cancer. $N$ Engl J Med, 350, 1945-52.

Boulmay BC, Chera BS, Morris CG, et al (2009). Definitive altered fractionation radiotherapy and concomitant weekly cisplatin for locally advanced head and neck cancer. $\mathrm{Am} J$ Clin Oncol, 32, 488-91.

Chan AT, Leung SF, Ngan RK, et al (2005). Overall survival after concurrent cisplatin-radiotherapy compared with radiotherapy alone in locoregionally advanced nasopharyngeal carcinoma. $J$ Natl Cancer Inst, 97, 536-9.

Chan AT, Teo PM, Ngan RK, et al (2002). Concurrent chemotherapy-radiotherapy compared with radiotherapy alone in locoregionally advanced nasopharyngeal carcinoma: Progression-free survival analysis of a phase III randomized trial. J Clin Oncol, 20, 2038-44.

Common Terminology Criteria for Adverse Events (CTCA)," NIH Publication (2009). [Online]. Available: https://evs. nci.nih.gov/ftp1/CTCAE/CTCAE_4.03_2010-06-14_ QuickReference_5x7.pdf.

Cooper JS, Pajak TF, Forastiere AA, et al (2004). Postoperative concurrent radiotherapy and chemotherapy for high-risk squamous-cell carcinoma of the head and neck. $N$ Engl $J$ Med, 350, 1937-44.

D'cruz A, Lin T, Anand AK, et al (2013). Consensus 
recommendations for management of head and neck cancer in Asian countries: A review of international guidelines. Oral Oncol, 49, 872-7.

Espeli V, Zucca E, Ghielmini M, et al (2012). Weekly and 3-weekly cisplatin concurrent with intensity modulated radiotherapy in locally advanced head and neck squamous cell cancer. Oral Oncol, 48, 266-71.

Fayette J, Molin Y, Lavergne E, et al (2015). Radiotherapy potentiation with weekly cisplatin compared to standard every 3 weeks cisplatin chemotherapy for loco-regionally advanced head and neck Squamous cell carcinoma. Drug Des Devel Ther, 9, 6203-10.

Forastiere AA, Zhang Q, Weber RS, et al (2013). Long-term results of RTOG 91-11: a comparison of three nonsurgical treatment strategies to preserve the larynx in patients with locally advanced larynx cancer. J Clin Oncol, 31, 845-52.

Geeta SN, Padmanabhan TK, Samuel J, et al (2006). Comparison of acute toxicities of two chemotherapy schedules for head and neck cancers. J Cancer Res Ther, 2, 100-4.

Geiger JL, Lazim AF, Walsh FJ, et al (2014). Adjuvant chemoradiation therapy with high-dose versus weekly cisplatin for resected, locally-advanced HPV/p16-positive and negative head and neck squamous cell carcinoma. Oral Oncol, 50, 311-8.

Ghosh-Laskar S, Chaukar D, Deshpande M, et al (2016). Phase III randomized trial of surgery followed by conventional radiotherapy ( $5 \mathrm{fr} / \mathrm{wk}$ ) (Arm A) vs concurrent chemoradiotherapy (Arm B) vs accelerated radiotherapy (6fr/ wk) (ArmC) in locally advanced, Stage III and IV, resectable, squamous cell carcinoma of oral cavity -oral cavity adjuvant therapy (OCAT): Final results (NCT00193843). J Clin Oncol, 34, 6004

Ghosh-Laskar S, Kalyani N, Gupta T, et al (2016). Conventional radiotherapy versus concurrent chemoradiotherapy versus accelerated radiotherapy in locoregionally advanced carcinoma of head and neck: Results of a prospective randomized trial. Head Neck, 38, 202-7.

Ghosh S, Rao PB, Kumar PR, et al (2015). Weekly cisplatin-based concurrent chemoradiotherapy for treatment of locally advanced head and neck cancer: A single institution study. Asian Pac J Cancer Prev, 16, 7309-13.

Gregoire V, Levendag P, Ang KK, et al(2003). CT-based delineation of lymph node levels and related CTVs in the node-negative neck: DAHANCA, EORTC, GORTEC, NCIC,RTOG consensus guidelines. Radiother Oncol, 69, 227-36.

Guan J, Zhang Y, Li Q, et al (2016). A meta-analysis of weekly cisplatin versus three weekly cisplatin chemotherapy plus concurrent radiotherapy (CRT) for advanced head and neck cancer (HNC). Oncotarget, 7, 70185-93.

Gupta T, Agarwal JP, Ghosh-Laskar S, et al (2009). Radical radiotherapy with concurrent weekly cisplatin in loco-regionally advanced squamous cell carcinoma of the head and neck: A single-institution experience. Head Neck Oncol, 1, 17.

Ho KF, Swindell R, Brammer CV (2008). Dose intensity comparison between weekly and 3-weekly cisplatin delivered concurrently with radical radiotherapy for head and neck cancer: A retrospective comparison from New Cross Hospital, Wolverhampton, UK. Acta Oncol, 47, 1513-8.

Kunieda F, Kiyota N, Tahara M, et al (2014). Randomized phase II/III trial of post-operative chemoradiotherapy comparing 3-weekly cisplatin with weekly cisplatin in high-risk patients with Squamous cell carcinoma of head and neck: Japan Clinical Oncology Group Study (JCOG1008). Jpn J Clin Oncol, 44, 770-4.

Kurihara N, Kubota T, Hoshiya Y, et al (1996). Pharmacokinetics of cis-diamminedichloroplatinum (II) given as low dose and high-dose infusions. J Surg Oncol, 62, 135-8.

Lee N, Harris J, Garden AS, et al (2009). Intensity-modulated radiation therapy with or without chemotherapy for nasopharyngeal carcinoma: radiation therapy oncology group phase II trial 0225. J Clin Oncol, 27, 3684-90.

Marcu L, Bezak E, Olver I (2006). Scheduling cisplatin and radiotherapy in the treatment of squamous cell carcinomas of the head and neck: a modelling approach. Phys Med Biol, 51, 3625-37.

Marcu L, van Doorn T, Olver I (2003). Cisplatin and radiotherapy in the treatment of locally advanced head and neck cancer-a review of their cooperation. Acta Oncol, 42, 315-25.

National Comprehensive Cancer Network (2017). NCCN clinical practice guidelines in oncology, NCCN Evidence Blocks: Head and neck cancers version 2.2017.https://www.ncen. org/professionals/physician_gls/pdf/head-and-neck.pdf.

Negi P, Kingsley PA, Srivastava H, et al (2016). Three weekly versus weekly cisplatin as radiosensitizer in head and neck cancer: A decision dilemma. Asian Pac J Cancer Prev, 17, 1617-23.

Noronha V, Joshi A, Maruti Patil V, et al (2017). Once-a-week versus once-every-3-weeks cisplatin chemoradiation for locally advanced head and neck cancer: A phase III randomized noninferiority trial. J Clin Oncol, 36, 1064-72.

Oosting SF, Chen TWW, Huang SH, et al (2016). A comparison of weekly versus 3-weekly cisplatin during adjuvant radiotherapy for high-risk head and neck cancer. Oral Oncol, 59, 43-9.

Otty Z, Skinner MB, Dass J, et al (2011). Efficacy and tolerability of weekly low-dose cisplatin concurrent with radiotherapy in head and neck cancer patients. Asia Pac J Clin Oncol, 7, 287-92.

Pignon JP, Bourhis J, Domenge C, Designe L (2000). Chemotherapy added to locoregional treatment for HNSCC: Three meta analyses of updated individual data. Lancet, 355, 949-55.

Pignon JP, Maitre AL, Bourhis J (2007). Meta analysis of chemotherapy in head and neck cancer (MACH-NC): An update. Int J Radiat Oncol Biol Phys, 69, 112-4.

Pignon JP, Maitre AL, Maillard E, Bourhis J (2009). Meta analysis of chemotherapy in head and neck cancer (MACH$\mathrm{NC}$ ): An update on 93 randomised trials and 17,346 patients. Radiother Oncol, 92, 4-14.

Quon H, Leong T, Haselow R, et al (2011). Phase III study of radiation therapy with or without cisplatinum in patients with unresectable Squamous or undifferentiated carcinoma of the head and neck: An intergroup trial of the Eastern Cooperative Oncology Group (E2382). Int J Radiat Oncol Biol Phys, 81, 719-25.

Rades D, Seidl D, Janssen S, et al (2016). Comparison of weekly administration of cisplatin versus three courses of cisplatin $100 \mathrm{mg} / \mathrm{m}(2)$ for definitive radiochemotherapy of locally advanced head-and-neck cancers. BMC Cancer, 16, 437.

Rawat S, Srivastava H, Ahlawat P, et al (2016). Weekly versus three-weekly cisplatin-based concurrent chemoradiotherapy as definitive treatment in head and neck cancer - where do we stand?. Gulf J Oncol, 1, 6-11.

Sahoo TK, Samanta DR, Senapati SN, et al (2017). A comparative study on weekly versus three weekly cisplatinum based chemoradiation in locally advanced head and neck cancers. J Clin Diagn Res, 11, 7-11.

Sharma A, Mohanti BK, Thakar A, et al (2010). Concomitant chemoradiation versus radical radiotherapy in advanced squamous cell carcinoma of oropharynx and nasopharynx using weekly cisplatin: A phase II randomized trial. Ann Oncol, 21, 2272-7. 
Szturz P, Wouters K, Kiyota N, et al (2017). Weekly low-dose versus three-weekly high dose cisplatin forconcurrent chemoradiation in locoregionally advanced non-nasopharyngeal head and neck cancer: A systematic review and meta-analysis of aggregate data. Oncologist, 22, 1056-66

Traynor AM, Richards GM, Hartig GK, et al (2010). Comprehensive IMRT plus weekly cisplatin for advanced head and neck cancer: The University of Wisconsin experience. Head Neck, 32, 599-606.

Tsan DL, Lin CY, Kang CJ, et al (2012). The comparison between weekly and three-weekly cisplatin delivered concurrently with radiotherapy for patients with postoperative high-risk squamous cell carcinoma of the oral cavity. Radiat Oncol, $7,215$.

Uygun K, Bilici A, Karagol H, et al (2009). The comparison of weekly and three-weekly cisplatin chemotherapy concurrent with radiotherapy in patients with previously untreated inoperable non-metastatic squamous cell carcinoma of the head and neck. Cancer Chemother Pharmacol, 64, 601-5.

\section{c) (7) (8)}

This work is licensed under a Creative Commons AttributionNon Commercial 4.0 International License. 